\title{
MEMORIA DE LA II LEGISLATURA EN EL SENADO
}

El período a que se refiere la presente Memoria, es el comprendido entre finales de 1982 y abril de 1986, mes este último en el que con la disolución anticipada de las Cámaras finaliza la II Legislatura.

El clima parlamentario durante este periodo, se encuentra influido, entre otras, por las siguientes circunstancias: triunfo del Partido Socialista en las elecciones generales que logra la mayoría absoluta en ambas Cámaras y con ello la formación de un Gobierno estable y homogéneo que supone la llegada al poder de la izquierda después de un largo período; la definitiva articulación del Estado de las Autonomías; el avance en la edificación de las libertades; el importante asunto de la expropiación de RUMASA el 23 de febrero de 1983, que daría lugar a una copiosa actividad parlamentaria y del propio Tribunal Constitucional; el referéndum sobre la permanencia de España en la OTAN que, no exento de tensiones dio origen a una intensa actividad politica y parlamentaria, y, por último, el ingreso de España en las Comunidades Europeas, que supondria la definitiva integración del país en las estructuras democráticas europeas. Todo ello, dentro de una supuesta tendencia al bipartidismo político entre el Partido Socialista y Coalición Popular, bipartidismo no claramente consolidado.

En definitiva, con la crónica parlamentaria referida al Senado no se pretende sino abordar, en el presente número de la Revista una memoria de la actividad de la Cámara Alta a lo largo de la anterior legislatura, sin perjuicio de la referencia a los proyectos de Ley que fueron reseñados en el número anterior, y que, por razones de exposición global de la memoria de dicha legislatura, son recogidos igualmente en esta relación.

Mencionaremos, asimismo, y aunque de forma sucinta, algunos aspectos concernientes a la configuración del Senado tal y como quedó 
perfilado tras las elecciones de 1982, con referencia a los grupos parlamentarios y territoriales que lo compusieron.

De igual modo, nos parece oportuno aludir a las intervenciones que han tenido lugar por parte de los órganos de gobierno del Senado, dado el carácter recopilador de la presente crónica sobre la actividad legislativa desarrollada por la Cámara Alta, así como a la de los órganos de funcionamiento, y a la intervención de la Diputación Permanente como órgano que representa la continuidad de la Cámara.

\section{COMPOSICION DEL SENADO}

Como se recordará, esta Cámara quedó compuesta por los 208 senadores elegidos directamente por el pueblo en las Elecciones Generales de octubre de 1982, y por 46 senadores designados por las Asambleas legislativas de las Comunidades Autónomas. La cifra total resultante: 254, no coincidirá siempre con el número real de miembros de la Cámara en consideración a las altas y bajas que, por diversas razones, se producen en la legislatura.

\section{CONFIGURACION DE LA CAMARA}

Esta configuración se basa en los grupos parlamentarios y territoriales que la componen:

\subsection{Grupos Parlamentarios}

Los senadores para el ejercicio de la actividad de la Cámara se agruparon en cinco grupos parlamentarios:

El Grupo Parlamentario Socialista, que quedó constituido por 138 miembros, al inicio de la legislatura, si bien el 23 de abril de 1986, sus miembros eran 153. Su portavoz fue D. Juan José Laborda Martín.

El Grupo Parlamentario Popular, que contó con 55 miembros al comienzo de la legislatura, viéndose posteriormente incrementado en número de 66, en fecha 23 de abril de 1986. Su portavoz fue D. Juan de Arespacochaga. 
El Grupo Parlamentario Senadores Nacionalistas Vascos, que contaba con 10 senadores al comienzo de la legislatura y que disminuyó a 9 el número de miembros en el momento de la disolución. Su portavoz fue D. Carmelo Renobales Vivanco.

El Grupo Parlamentario Cataluña al Senado, que también ha sufrido bajas en su composición a lo largo de la legislatura, pasando de 10 a 7 senadores. Su portavoz fue D. Ramón Sala i Canadell.

El Grupo Mixto, contaba el 23 de abril de 1986 con 15 senadores, frente a los cinco con que se constituyó inicialmente. Es una peculiaridad de este grupo la de no disponer de portavoz fijo, actuando como tal, sus diversos componentes y durante un período limitado de tiempo.

\subsection{Grupos territoriales}

Junto a los grupos parlamentarios tradicionales, en los que los senadores se asocian por afinidad ideológica, existen en el Senado, dado que se trata de una Cámara de representación territorial, Grupos Parlamentarios territoriales que tratan de reflejar la organización autonómica del Estado, habiéndose constituido hasta un total de veintinueve.

\section{ORGANOS DEL GOBIERNO DE LA CAMARA ALTA}

\subsection{La Mesa}

Como órgano rector del Senado se articula la Mesa, constituida por un Presidente, dos Vicepresidentes y cuatro Secretarios.

Quedó definitivamente constituida el 18 de diciembre de 1982, manteniéndose inalterable en su composición durante toda la Legislatura.

Las personas que han integrado la Mesa han sido:

Presidente: D. José Federico de Carvajal Pérez

Vicepresidente 1. ${ }^{\circ}$ : D. Arturo Lizón Giner

Vicepresidente 2. ${ }^{\circ}$ : D. Juan Carlos Guerra Zunzunegui

Secretario 1. ․ D. José Luis Rodriguez Pardo 
Secretario 2..: D. a María Luisa Urcelay López de las Heras

Secretario 3. : D. Ignacio Gaminde Alix

Secretario 4. ${ }^{\circ}$ : D. Fernando Gil Nieto

El número de sesiones celebradas por la Mesa a lo largo de la legislatura ha sido de 140, siendo su distribución anual la siguiente:

\begin{tabular}{|c|c|}
\hline Durante 1982 & ............. \\
\hline Durante 1983 & ............ \\
\hline Durante 1984 & ........... \\
\hline Durante 1985 & \\
\hline urante 1986 & \\
\hline
\end{tabular}

Se observa, en consecuencia, un gran esfuerzo del órgano rector del Senado durante los años 1983, 1984 y 1985 que representan el cuerpo de la Legislatura, ya que los años 1982 y 1986 corresponden al inicio y final de la misma.

\subsection{Junta de Portavoces}

La organización del trabajo de la Cámara es de trascendental importancia para la rapidez y eficacia del Senado. Para facilitar esta labor cobra especial relieve la Junta de Portavoces, compuesta por el Presidente de la Cámara y los portavoces de los distintos grupos parlamentarios.

Sustituye al Pleno en la adopción de decisiones que tradicionalmente le corresponderían, redundando en un importante ahorro de tiempo. El Gobierno asiste a estas reuniones por medio de representante.

De la actividad de la Junta de Portavoces da clara idea el número de sesiones celebradas, que ha sido de 116 a lo largo de la legislatura, con una distribución máxima en los años 1983, 1984 y 1985 como corresponde a lo que hemos llamado cuerpo de la legislatura y que representa un total de 103 sesiones. 


\section{ORGANOS DE FUNCIONAMIENTO} misiones.

Distinguiremos dos órganos de funcionamiento: el Pleno y las Co-

\subsection{El Pleno}

Forman parte del Pleno todos los miembros de Derecho de la Cámara, y durante el periodo legislativo ha celebrado un total de setenta y ocho sesiones, distribuidas de la siguiente forma:

\begin{tabular}{|c|c|}
\hline Año 1982 & .................. \\
\hline Año 1983 & ................. \\
\hline Año 1984 & .................. \\
\hline Año 1985 & ............... \\
\hline
\end{tabular}

\subsection{Las Comisiones}

Reglamentariamente, el Senado tiene catorce Comisiones legislativas, cinco Comisiones generales y dos Comisiones permanentes no legislativas. Además, $y$, de acuerdo con las previsiones orgánicas de este organismo, se han creado hasta un total de seis Comisiones de Investigación o Especiales.

Por otra parte, es digna de mencionar la Comisión de Seguimiento del Fondo de Compensación Interterritorial, que fue ya determinada en la propia Ley reguladora del mismo, la Comisión mixta Congreso de Diputados-Senado para las relaciones con el Tribunal de Cuentas y, por último, una de carácter mixto para las Comunidades Europeas, creada por la Ley de Bases de delegación para la ejecución del Derecho Comunitario.

De manera sumaria, destacaremos la actividad de las Comisiones 
que durante la legislatura han desarrollado, a nuestro juicio, una muy intensa labor, tanto cualitativa como cuantitativa, y que, atendiendo a este último aspecto, y por el número de sesiones celebradas, queda reflejado en el siguiente resumen:

a) Dentro de las Comisiones Generales, destaca la Comisión de Peticiones que ha celebrado un total de treinta y cinco sesiones, seguida de la de de Suplicatorios.

En total asciende a cuarenta y ocho el número de sesiones celebradas por todas las Comisiones.

b) Respecto a las Comisiones Legislativas, destaca la de Justicia con treinta y nueve sesiones, seguida de la de Presupuestos y la de Economía y Hacienda. En total el número de sesiones de las catorce Comisiones legislativas ascendió a 216.

Las sesiones informativas han sido importantes en materias trascendentales para la Nación, tal como Presidencia e Interior, Industria y Asuntos Exteriores o Autonomías.

c) Respecto de las Comisiones permanentes no legislativas es de destacar la de Asuntos Iberoamericanos con dieciocho sesiones, seguida de la de Relaciones con el Defensor del Pueblo y de los Derechos Humanos, con trece. El total de sesiones ascendió a treinta y una.

d) El capítulo de Comisiones especiales recoge las creadas con motivo de problemas de singular e inmediata relevancia, que por sus características reclamaban la intervención de la Cámara. El total de Comisiones de Investigación o Especiales, creadas durante la II Legislatura, ya finalizada, asciende a siete, entre las que cabe citar: las relacionadas con el problema de la droga; situación de los puertos españoles, y de los trabajadores emigrados a Europa. El total de sesiones de este grupo ascendió a sesenta y dos.

Hemos querido reflejar globalmente la actividad numérica de las Comisiones del Senado, porque es reflejo de la gran actividad legislativa que se ha desarrollado durante la II Legislatura en las Cortes Españolas $y$, concretamente, en el Senado que, ha supuesto una clara línea del progreso legislativo de la Nación como Estado de Derecho. 


\section{ORGANO DE CONTINUIDAD: LA DIPUTACION PERMANENTE}

Cuando la Cámara no está en período de sesiones, la Diputación Permanente es el órgano que debe de velar por los poderes que a aquélla corresponden.

La preside el Presidente de la Cámara y está compuesta por un mínimo de veintiún miembros que representan a los grupos parlamentarios, en proporción a su importancia numérica. El Pleno, antes de elegirlos, fija el número exacto de miembros de este órgano.

Su composición en la presente Legislatura se distribuyó en: diecisiete miembros del Grupo Socialista, siete del Grupo Popular, y uno de cada uno de los grupos Cataluña al Senado, Senadores Nacionalistas Vascos, y Grupo Mixto, con un total de veintisiete miembros.

La mesa de la Diputación Permanente la preside el Presidente de la Cámara y se compone de dos Vicepresidentes y dos Secretarios.

Durante la pasada Legislatura la Diputación Permanente se reunió en tres ocasiones, destacando la sesión del 18 de julio de 1984 para resolver sobre la Petición de Pleno extraordinario en relación con la entrada de España en la CEE.

\section{ACTIVIDAD DEL SENADO}

El Senado desarrolla, fundamentalmente, una actividad legislativa y de control a la que haremos principal referencia. Esta actividad supone la ejecución de la competencia constitucional atribuida a esta Cámara en nuestro sistema democrático.

Junto a esta actividad $y$, al margen de toda competencia constitucional, existe otra acción de carácter interparlamentario, científico y cultural de la que, aunque brevemente, haremos también la correspondiente referencia.

\subsection{Actividad legislativa}

La actividad legislativa, función constitucional atribuida al Senado en el ámbito de su competencia, ha de entenderse referida a la tramitación de proyectos de ley, a la presentación de proposiciones de ley y a los tratados internacionales. 
La especificidad de estos grupos exige un tratamiento particular de cada figura:

\subsubsection{Proyectos de ley}

El total de proyectos de ley tramitados por el Senado asciende a 201, de los que treinta y nueve tienen el carácter de Ley Orgánica.

El Senado ha modificado 107 proyectos de ley, estando tres en tramitación al concluirse la Legislatura.

Al no ser posible el comentario sobre cada uno de ellos, ni siquiera de aquéllos más importantes, por razones obvias de espacio, relacionaremos los más importantes, agrupándolos por materias y según su orden cronológico:

a) Autonomias, organización y administración territorial

- Proyecto de Ley Orgánica del Estatuto de Autonomía de Madrid.

- Proyecto de Ley Orgánica del Estatuto de Autonomía de las Islas Baleares.

- Proyecto de Ley Orgánica del Estatuto de Autonomía de Extremadura.

- Proyecto de Ley Orgánica del Estatuto de Autonomía de Castilla y León.

- Proyecto de Ley Orgánica sobre desarrollo del artículo 154 de la Constitución.

- Proyecto de Ley de incentivos regionales para la corrección de desequilibrios económicos interterritoriales.

- Proyecto de Ley Reguladora de las Bases de Régimen Local.

b) Economía, Hacienda y Presupuestos

- Proyecto de Ley de medidas urgentes en materia presupuestaria, financiera y tributaria. 
- Proyecto de Ley de Expropiación por razones de utilidad pública e interés social de los bancos y otras sociedades que componen al grupo Rumasa (R.D. Ley $2 / 1983$ de 23 de febrero).

- Proyecto de Ley de los Presupuestos Generales del Estado de 1983.

- Proyecto de Ley del Fondo de Compensación Interterritorial.

- Proyecto de Ley de medidas financieras de estímulo a la exportación.

- Proyecto de Ley Orgánica por el que se modifica la Ley 40/1977 de 10 de diciembre sobre régimen jurídico de control de cambios.

- Proyecto de Ley de Medidas urgentes de saneamiento y regulación de las Haciendas Locales.

- Proyecto de Ley de Presupuestos Generales del Estado de 1984.

- Proyecto de Ley regulador de la cesión de Tributos del Estado a las Comunidades Autónomas.

- Proyecto de Ley sobre ordenación del Seguro Privado.

- Proyecto de Ley por el que se fijan los porcentajes de participación de las Comunidades Autónomas en los ingresos del Estado de 1984.

- Proyecto de Ley reguladora de las Instituciones de Inversión colectiva.

- Proyecto de Ley de Presupuestos Generales del Estado para 1985.

- Proyecto de Ley de coeficientes de inversión, recursos propios y obligaciones de información de los intermediarios financieros.

- Proyecto de Ley de Régimen fiscal de determinados activos financieros. 
- Proyecto de Ley Orgánica de Reforma del Código Penal en materia de delitos contra la Hacienda Pública.

- Proyecto de Ley Cambiaria y del Cheque.

- Proyecto de Ley Reguladora de las normas básicas sobre órganos rectores de las Cajas de Ahorros.

- Proyecto de Ley de Impuestos Especiales.

- Proyecto de Ley del Impuesto del Valor Añadido.

- Proyecto de Ley de Reforma Parcial del Impuesto sobre la Renta de las Personas Físicas.

- Proyecto de Ley de Presupuestos Generales del Estado para 1986.

c) Justicia

- Proyecto de Ley Orgánica de Reforma de los artículos 503 y 504 de la Ley de Enjuiciamiento Criminal.

- Proyecto de Ley Orgánica de Reforma Urgente y Parcial del Código Penal.

- Proyecto de Ley de Reforma del Código Civil en Materia de Tutela.

- Proyecto de Ley Orgánica sobre modificación de las competencias de la Audiencia Nacional.

- Proyecto de Ley Orgánica por la que se desarrolla el artículo 17.3 de la Constitución en materia de asistencia Letrada al detenido y al preso, y de modificación de los artículos 520 y 527 de la Ley de Enjuiciamiento Criminal.

- Proyecto de Ley Orgánica de Reforma del artículo 417 bis del Código Penal.

- Proyecto de Ley por el que se modifica el artículo 338 de la Ley de Enjuiciamiento Criminal. 
- Proyecto de Ley Orgánica reguladora de los procedimientos de Habeas Corpus.

- Proyecto de Ley sobre reforma Urgente de la Ley de Enjuiciamiento Civil.

- Proyecto de Ley de Extradición pasiva.

- Proyecto de Ley Orgánica del Poder judicial.

- Proyecto de Ley Orgánica de reforma del artículo 417 bis, del Código Penal.

- Proyecto de Ley de Supresión de Tasas judiciales.

d) Defensa

- Proyecto de Ley de reforma de la Ley Orgánica 6/1980, de 1 de julio, por la que se regulan los criterios básicos de la defensa nacional y la organización militar.

- Proyecto de Ley de Servicio militar.

- Proyecto de Ley reguladora de la Objeción de Conciencia, y de la prestación social sustitutoria.

- Proyecto de Ley de unificación de los Cuerpos de Intervención militar, de Intervención de la Armada y de Intervención del Aire.

- Proyecto de Ley. Orgánica del Código Penal militar.

- Proyecto de Ley Orgánica de régimen disciplinario de las Fuerzas Armadas.

- Proyecto de Ley de plantillas del Ejército del Aire.

- Proyecto de Ley de plantillas de la Armada.

\section{e) Educación y Universidades}

- Proyecto de Ley de medidad urgentes, en materia de órganos de gobierno de las Universidades. 
- Proyecto de Ley Orgánica de Reforma Universitaria.

- Proyecto de Ley Orgánica reguladora del Derecho a la Educación.

- Proyecto de Ley del Consejo Social de las Universidades.

f) Interior y orden público

- Proyecto de Ley Orgánica Reguladora del Derecho de reunión.

- Proyecto de Ley Orgánica reguladora del Derecho de rectificación.

- Proyecto de Ley reguladora del Derecho de Asilo y de la condición de refugiado.

- Proyecto de Ley Orgánica contra la Actuación de bandas armadas y elementos terroristas y de desarrollo del artículo 55.2. de la Constitución.

- Proyecto de Ley sobre protección civil.

g) Trabajo, Seguridad Social y actividad sindical.

- Proyecto de Ley Orgánica de Libertad Sindical.

- Proyecto de Ley sobre modificación de determinados artículos de la Ley 8/80 de 10 de marzo, del Estatuto de los Trabajadores.

- Proyecto de Ley de protección por desempleo por el que se modifica el Título II de la Ley 51/1980 de 8 de ocubre.

- Proyecto de Ley de medidas urgentes para la racionalización de la estructura y de acción protectora de la Seguridad Social.

- Proyecto de Ley General de Sanidad.

- Proyecto de Ley General de Cooperativas. 
h) Otros proyectos de Ley

- Proyecto de Ley de organización de la Administración Central del Estado.

- Proyecto de Ley Orgánica de regulación de la iniciativa legislativa Popular.

- Proyecto de Ley General para la defensa de los consumidores y usuarios.

- Proyecto de Ley de medidas urgentes para la reforma de la Función Pública.

- Proyecto de Ley de reconversión y reindustrialización.

- Proyecto de Ley Orgánica del régimen Electoral General.

- Proyecto de Ley Orgánica sobre derechos y libertades de los extranjeros en España.

- Proyecto de Ley Orgánica de autorización para la adhesión de España a las Comunidades Europeas.

- Proyectos de Ley de bases de delegación al Gobierno para la aplicación del Derecho Comunitario.

\subsubsection{Proposiciones de Ley}

Como establece el artículo 87 de la Constitución, la iniciativa legislativa corresponde al Gobierno, al Congreso y al Senado, de acuerdo con el propio texto constitucional y los Reglamentos de las Cámaras.

Concretamente regulan el procedimiento de iniciativa legislativa del Senado los artículos 108 y 109 de su Reglamento, en los que se establecen los requisitos y el procedimiento a seguir.

Refiriéndonos a la pasada Legislatura, el Senado ha tramitado veinte proposiciones de Ley. De ellas cinco fueron presentadas por el Grupo Parlamentario Popular, tres no fueron tomadas en consideración y dos fueron retiradas, siete se presentaron al Senado y cuatro sufrieron modificaciones en él, estando, finalmente, una pendiente de tramitación al terminar la Legislatura. 

neral:

Destacaremos como más importantes, en razón de su interés ge-

- Proposición de ley de modificación del tipo de interés legal del dinero.

- Proposición de ley sobre tipificación penal de la colocación ilegal de escuchas telefónicas.

- Proposición de ley con el fin de que desaparezca la discriminación en el trato que reciben por la Ley 46/1977 de 15 de octubre, los militares profesionales de la República, respecto e los funcionarios civiles comprendidos en dicha ley.

- Proposición de Ley Orgánica por la que se deroga el Capítulo II del Título VI de la Ley Orgánica $2 / 1979$, de 3 de octubre, reguladora del Tribunal Constitucional.

- Proposición de Ley Orgánica 1/82, de 5 de mayo, sobre protección del Derecho al Honor a la intimidad, personal, y familiar y a la propia imagen.

\subsubsection{Tratados Internacionales}

La actividad desarrollada por el Senado en relación con acuerdos internacionales puede calificarse de excepcional, como lo prueba el elevado número de ellos que han sido tramitados durante la Legislatura, todo ello en lógica consonancia con la progresiva integración y participación de España en el marco internacional.

Así, nada menos que 133 acuerdos internacionales han sido tramitados en la pasada legislatura, estando, al final de la misma, otros ocho pendientes.

Es evidente que ha dado su volumen, no podemos ni siquiera agruparlos, por lo que seleccionamos los que, a nuestro juicio, son más importantes, como muestra y síntesis informativa del trabajo, en este campo, de nuestra Alta Cámara:

- Ratificación del Convenio de amistad, defensa y cooperación entre el Reino de España y los Estados Unidos de América, firmado en Madrid el día 2 de julio de 1982, y Protocolo de dicho convenio firmado en Madrid el 24 de febrero de 1983. 
- Convenio para la constitución de una Organización Europea para la investigación Nuclear.

- Declaración del Estado Español relativa al artículo 41 del·Pacto Internacional de Derechos Civiles y Políticos adoptado por la Asamblea General de Naciones Unidas el 19 de diciembre de 1966.

- Denuncia del Acuerdo entre España y los países de la Asociación Europea de Libre Cambio.

\subsection{Función de Control}

El Senado desarrolla una importante labor de crítica e inspección del Gobierno, que se ha materializado en las siguientes actuaciones que, globalizadas numéricamente y correspondientes al período legislativo, exponemos a continuación:

a) Preguntas Escritas:

Total correspondientes a la legislatura: 575 , de las cuales fueron retiradas 12 , enviadas a comisión 22 , no admitidas 94 , pasadas a pregunta oral dos, pendientes $352 \mathrm{y}$ el resto contestadas.

b) Preguntas orales: tura.

Fueron presentadas un total de 419 a lo largo de toda la Legisla-

c) Preguntas orales urgentes: 71 .

d) Interperlaciones: 139.

e) Interpelaciones urgentes: 37 .

f) Mociones: 62 . 


\subsection{Otras actividades del Senado}

Hasta aquí hemos visto las funciones parlamentarias que constitucionalmente tiene atribuidas el Senado.

Sin embargo, no podemos dejar de reflejar otras actividades que desarrolla esta Cámara y que debemos de calificar de importantes.

En efecto, el Senado desarrolla una actividad de relación con Parlamentos e instituciones de otros países extranjeros, asi como de asistencia y participación en organismos internacionales. Le corresponde, por otra parte, una serie de actuaciones oficiales de variado carácter que integran lo relativo al Protocolo. numéricos:

Dentro de esta actividad podemos destacar sin descender a datos

- Visitas de Altas Autoridades.

- Visitas de Delegaciones Parlamentarias.

- Visitas del Presidente del Senado.

— Visitas de Delegaciones del Senado.

- Actos Oficiales.

\subsection{Obra Cultural y Científica del Senado}

Durante esta Legislatura se ha realizado una relevante labor de restauración del Palacio del Senado, incluida su Pinacoteca, integrada por una importante colección de carácter histórico del siglo XIX.

Asimismo, se han restaurado fondos antiguos de la Biblioteca, como igualmente valiosos mobiliarios y enseres.

Por otra parte, es de destacar la labor de la Mesa de la Cámara, que con importantes adquisiciones, ha enriquecido el patrimonio artístico del Senado. tífico.

Análogamente, ha sido objeto de atención especial el campo cien-

Dentro de todas estas actividades pueden destacarse:

- La publicación del Boletín de las Comunidades Autónomas. 
- El Libro del Palacio del Senado.

- El enriquecimiento de los fondos de la Biblioteca del Senado.

- Becas y concursos diversos.

Toda esta labor, a nuestro juicio, merece el elogio que representa la contribución del Senado al desarrollo de actividades y manifestaciones que son ciertamente importantes en la vida del Estado.

M. ${ }^{a}$ VICTORIA GARCIA-ATANCE 